\title{
Encontré un icnofósil y tampoco supe qué hacer con él
}

Eduardo Mayoral Alfaro | Dpto. de Ciencias de la Tierra, Facultad de Ciencias Experimentales, Universidad de Huelva

URL de la contribución <www.iaph.es/revistaph/index.php/revistaph/article/view/4158>

Tomando como inspiración el título del texto introductorio de la coordinadora de este debate, mi querida Eloísa Bernáldez, me gustaría incidir y profundizar en algunas reflexiones que ella hace en el mencionado texto, entre otras cosas, porque ambos hemos sufrido los avatares y sinsabores acerca del devenir del patrimonio paleontológico en Andalucía.

El patrimonio paleontológico debe tener su propio marco legal, al igual que ocurre con el arqueológico, y del que nadie, desde la administración hasta la sociedad, tiene dudas de que debe de estar protegido, como así ocurre. Las razones que lo justifican son obvias. Los yacimientos paleontológicos (los fósiles) son elementos que forman parte del patrimonio geológico y se constituyen como georrecursos que son rasgos esenciales de la geodiversidad y esto, como se puede deducir, no tiene nada que ver con el patrimonio arqueológico. Por desgracia, en la Comunidad Autónoma de Andalucía, la situación es lamentable y penosa. Lo "paleontológico" solo queda recogido de pasada en la Ley 16/1985 de Patrimonio Histórico Español y ligado siempre a la historia del hombre, sus orígenes y antecedentes, siendo materia de estudio mediante la realización de excavaciones arqueológicas.

También es cierto que la tipología de algunos yacimientos de fósiles "no humanos" pueden acogerse a alguna figura de protección legal dentro de la ley anterior (monumento, conjunto histórico, sitio histórico o zona arqueológica); e incluso todos ellos son susceptibles de inscribirse por su interés para la comunidad autónoma como bien de interés cultural dentro del Catálogo General del Patrimonio Histórico Andaluz. Hasta aquí todo casi perfecto, pero luego topamos con la exasperante lentitud burocrática de la administración. Un ejemplo, el yacimiento de medusas fósiles del Cámbrico inferior de Constantina en la provincia de Sevilla. Este yacimiento fue dado a conocer por Liñán y Mayoral (1992), hallazgo que fue puesto en conocimiento de la Consejería de Cultura de la Junta de Andalucía; por entonces, el organismo que tenía competencias en esta materia. Posteriormente, tras doce años de investigación, el yacimiento fue publicado en extenso y difundido a la comunidad científica (MAYORAL; LIÑÁN; GÁMEZ VINTANED et ál., 2004). Este yacimiento es, sin duda, uno de los más importantes del mundo en cuanto al registro de estos organismos de cuerpo blando, tanto en cantidad (más de 90 ejemplares) como en calidad (tamaños excepcionales de hasta $88 \mathrm{~cm}$ de longitud). Y, junto a otros, ha sido uno de los principales argumentos que han servido para que, en septiembre de 2015, la UNESCO declarase como geoparque mundial al Geoparque de la Sierra Norte de Sevilla, lugar en el que se ubica dicho yacimiento. Desde entonces, han pasado otros 14 años y todavía la administración andaluza no ha hecho efectiva la figura de su protección como monumento natural (una de las pocas figuras que concede la legislación actual), a pesar incluso de su difusión a la comunidad científica internacional (GIL TOJA; SANZ MATENCIO; MAYORAL, 2016).Si un yacimiento de esta importancia tiene que esperar 36 años (¡de momento!) a que sea declarada una figura de protección legal para el mismo es que vamos por mal camino. $Y$ todo esto se deriva, como es lógico, de la inexistencia de una ley que permita su tratamiento correcto, con la toma de medidas efectivas y adecuadas para evitar que se pierda de forma irremediable, como en este caso, una de las joyas de nuestro inmenso y rico patrimonio paleontológico.

Por todo, la protección del patrimonio paleontológico es muy importante. El principal motivo, por la salvaguarda de todos aquellos yacimientos que no contienen fósiles humanos (protegidos por la ley anterior). Esto hace ( $y$ ha hecho) que muchos yacimientos o hallazgos importantes 
a debate El marco legal para la protección del patrimonio paleontológico. ¿Qué pasa en tu comunidad?
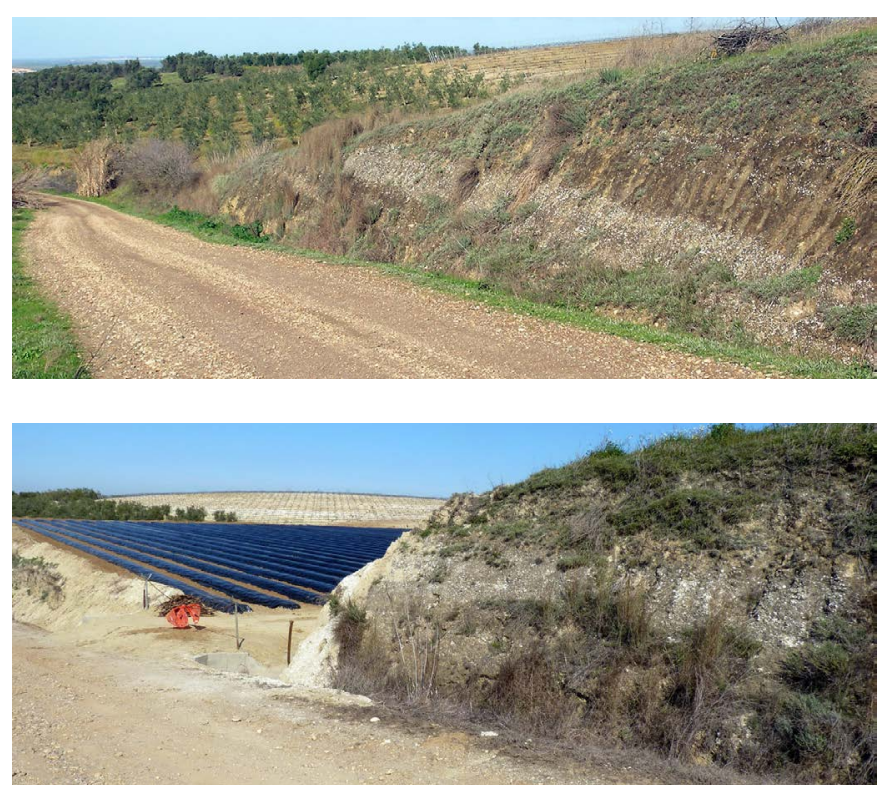

Vista general del afloramiento de fósiles del Plioceno inferior del paraje de Las Presas en Villarrasa (Huelva). Arriba, mayo de 2014, cuando se conservaba todo el tramo inferior y medio de la serie estratigráfica con sus niveles fósiles. Abajo, mayo de 2015; la parte inferior de la sección ha desaparecido por la instalación de un cultivo de aloe vera | fotos Eduardo Mayoral Alfaro

hayan sido expoliados y/o destruidos, ya sea de forma intencionada (coleccionismo), por desconocimiento (realización de obras públicas o intervenciones antrópicas) o por desidia por parte de la administración. En esta línea, el papel del paleontólogo/a es esencial, ya que los investigadores especializados en Paleontología son los únicos profesionales capacitados para abordar con conocimiento de causa cualquier proyecto de investigación de esta índole o de cualquier actuación de carácter patrimonial. Los requisitos, tener formación paleontológica acreditada, independientemente si se procede de los grados de Geología o Biología. En la actualidad, en la comunidad andaluza los únicos proyectos de "paleontología" están regulados como actividades arqueológicas y los investigadores responsables ya no pueden ser paleontólogos, sino las personas físicas, nacionales o extranjeras, que cuenten con titulación académica de licenciatura en el ámbito de las Humanidades y que acrediten una formación teórica en arqueología (LEY 14/2007). Si esto no es un caso claro de intrusión profesional...
Por último, siguiendo el hilo argumental propuesto, el uso de las nuevas tecnologías siempre es positivo si éstas se aplican de la forma correcta y están encaminadas a la consecución de fines que tengan que ver con una buena gestión de uso y conservación de los fósiles y sus yacimientos. Hoy en día, las técnicas de geolocalización, por ejemplo, nos permiten tener un mayor control de la situación exacta de estos, en ocasiones ubicados en lugares remotos, lo que permite o facilita aspectos como su inventario y cuestiones relacionadas con su "explotación". Sin embargo, estas mismas tecnologías hacen que algunos yacimientos sean muy frágiles frente a actividades de expolio o coleccionismo incontrolado. De ahí, que sea necesario e imprescindible contar con una legislación que pueda contemplar de forma adecuada todas estas y otras muchas posibilidades, dirigidas siempre a la protección y conservación de todos estos bienes naturales de indudable valor cultural y patrimonial.

\section{BIBLIOGRAFÍA}

- GIL TOJA, A.; SANZ MATENCIO, A.; MAYORAL (2016) New Natural Monument: Lower Cambrian jellyfish impressions (Sierra Norte de Sevilla Geopark). En 7th International Conference on UNESCO Global Geoparks, Torquay, United Kingdom - Riviera International Conference Centre [en línea] p. 106 <http://www.globalgeopark.org/UploadFiles/2016_11_2/ Abstract_Book\%20of\%20the\%207th\%20international\%20 conference\%20on\%20UNESCO\%20Global\%20Geoparks. pdf> [Consulta: 10/04/2018]

- LEY 14/2007, de 26 de noviembre, del Patrimonio Histórico de Andalucía. Boletín Oficial de la Junta de Andalucía, n. ${ }^{\circ} 248$, de 19 de diciembre de 2007

- LEY 16/1985, de 25 de junio, del Patrimonio Histórico Español. Boletín Oficial del Estado, n. ${ }^{\circ} 155$ de 29 de junio de 1985, pp. 20342-20352

- LIÑÁN, E.; MAYORAL (1992) Medusoides del Cordubiense (Cámbrico basal) de Sevilla. VII Jornadas de la Sociedad Española de Paleontología, Oviedo (España). Oviedo: Universidad, 1992, p. 40

- MAYORAL, E.; LIÑÁN, E.; GÁMEZ VINTANED, J. A.; MUÑIZ, F.; GOZALO, R. (2004) Stranded jellyfish in the lowermost Cambrian (Corduban) of Spain. Revista Española de Paleontologia, vol. 19, n. ${ }^{\circ} 2,2004$, pp. 191-198 